\title{
Research on the Developmental Trend of CG Technology in Hollywood and the Influence on Chinese Film and Television Production
}

\author{
Yuting Cui \\ Hebei University, \\ Baoding,Hebei,071000 China
}

\author{
Wantong Cao \\ Hebei University, \\ Baoding,Hebei,071000 China
}

\begin{abstract}
In this paper, we conduct basic research on the developmental trend of CG technology in Hollywood and the influence on Chinese film and the television production. The film's real, this should not be true of physical reality, and should be a real art. Under the real line of art, is the creation subject, communicators, accepts the main body of the social era, cultural environment and its moral conscience and the humanities. Virtual reality technology in the development of today, no we can't do, only we believe technology as a means of implementation, not only need theory to guide, also need the discretion of moral criterion. Which is involved in the film wonders of all, need thoughtful, measure the questions very carefully. In the angle of modern CG illustration artistic creation, it is the creation of raw materials, inspiration and the material. It can go, deformation, transplantation, restructuring, and so on, finally achieve the goal of creating a new illustration works. Our research proposes the new paradigm for the Chinese film and the television production that is innovative.
\end{abstract}

Keywords- Developmental Trend, CG Technology, Hollywood, Chinese, Film and Television.

\section{Introduction}

The film and the television works is the spiritual sustenance of people's life, and a film and television works is the need to rely on the film and television opening to attract the attention of the audience. Therefore, in the general process of making the TV and movies to appeal to the aesthetic trend of the development and achieve the perfect combination of art and technology, improve the influence of film and television works. Film opening is special art design, with the characteristics of movie pictures no visual perception of a certain standard is made up of people of their respective interests and culture. Early in the development of the film titles, the designers design elements are made by hand, using the camera, and then edit and the development of modern technology effectively improve the efficiency of the traditional hand-made, enrich the opening screen, don't make the opening design artistic breath. With effective combination of information technology and art in the 3D technology into photography, painting and the other art forms, bring more realistic visual wallop, and widely used. Film titles, so to speak, therefore, with making a process of the constant development, gradually to the basic pursuit of characteristic and the individuality of road performance [1-3].

As we have seen, globalization and social transformation does bring an era of value pluralism. In this era, people no longer easily superstition authority, but to have the opportunity to make a variety of the judgment and choice, this undoubtedly provides human society with more freedom, more progress forward direction. Hollywood movie has a far-reaching influence on modern people, when we are impressed by its special effect, beautiful pictures and stage actor superb acting, whether to see the Hollywood movie is not just pay attention to the effect of the external while it pay more attention to permeate 
an ethical culture in the ordinary movie scenarios.

$\mathrm{CG}$ animation that computer animation since birth in the lab, screen, enter the Internet, to appear in the my cell phone, only after a short decades, and CG animation along with the rapid development of computer technology, in a variety of forms exist in a variety of media, some for scientific research, some for artistic creation, some entertainment for the masses, has many functional. The diversity and universality, prompting $\mathrm{CG}$ animation visual representation methods are constantly improve, to adapt to the requirements of richness and diversity of information content, with the continuous development of CG animation technology, the CG animation with the unprecedented image expression ability, and gradually formed its own unique image visual performance characteristics. Feeling of space and time is composed of visual space and time image, the basis of visual expression in the real world as people are the only space forever with the certain speed toward a direction of the timeline. In animation, space and time are relative and not the only, spatial and temporal variation is a traditional animation explore the important form of image visual expression breakthrough in the $\mathrm{CG}$ animation, reflect the spatial and temporal variation characteristics means more rich as form is more extensive. At the same time, by the application of computer technology, as a result of new relationship between visual shows with the audience to $\mathrm{CG}$ animation image visual expression of characteristics of new type as in figure one as the follows, we demonstrate the contemporary CG technology in the Hollywood [4-5].

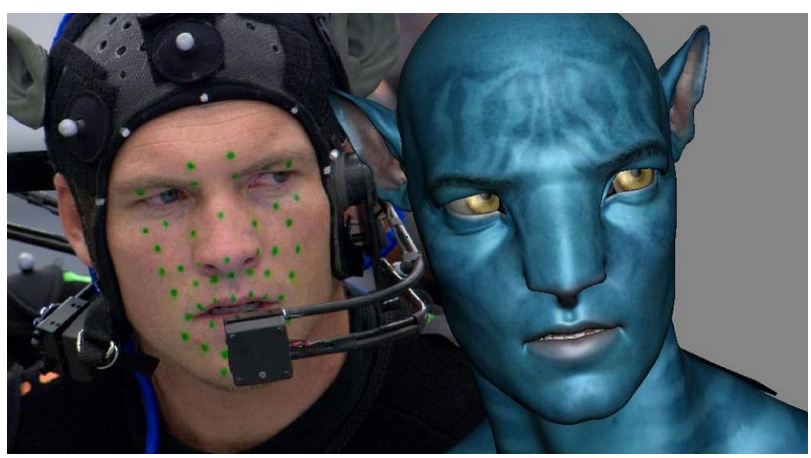

Figure 1. The Demonstration of CG Technology in Hollywood

In this paper, we conduct research on the developmental trend of $\mathrm{CG}$ technology in Hollywood and the influence on Chinese film and the television production. China's film and television animation industry under the government strongly promote fast development with the production of animation works to further improve domestic animation original ability animation industry chain is preliminary formed. At present, should be settled as soon as possible influence of the Chinese film and television animation in some deep-seated problems and contradictions in the process of industrialization. In the later sub-sections, we will propose our perspectives and discussions in detail.

\section{Our Proposed Perspective}

The Characteristics of the Hollywood. The United States Hollywood film since birth is leading the world trend, the vanguard of occupies the dominant position in contemporary film. According to the analysis of Hollywood movie art make it cannot fully master the art of style, whether through a film production company or independent films, because of the richness and the diversity of films formed today's movie art development situation, the variability and full of imagination thinking and stunning visual effects. And, therefore, regardless of Hollywood movies cost of investment, its unique film art style also is worthy of our learning [6-7].

The location of the Hollywood is in the Los Angeles, California in the United States, many 
movie companies in the United States set up here, so is famous for the Hollywood is the name. With its large number for the headquarters of the movie company, dream factory, Disney, Columbia pictures, SONY, universal, the Warner Brothers film company, and so on. These films from the film company almost involve all levels and all ages, so the impact of various aspects. In addition to the film industry, Hollywood records, the fashion industry. In recent years, the United States export output value of the film industry after industry, showing time $80 \%$ of the world movie show time while it also shows the United States headed by Hollywood film to around the world, the impact of Hollywood culture under the background of supported by advanced science and technology and all kinds of social ideas of the current us subsequently spread to various countries with the impact on the people all over the world.
Hollywood movie art style as the change of trend of the times will happen corresponding change, but to properly evaluate the specific style is an elusive thing, although the aesthetics characteristic of current Hollywood movies are through the image of display, but through these images reveal art style, like Hollywood movie itself, as does not generate a fixed pattern, so is a broad external interface. At present, with the new media was once become one of the factors determining the film art, the pursuit of innovation and form modern creation concept to promote the film to the trend of marginalization. At the same time, visual theory and western philosophical thoughts in different extent mutations lead to the Hollywood movie art style, the contemporary Hollywood films to the creation of fine arts has shown diversity, and actively to break the traditional interface, the performance of the film is not the same way. The figure three demonstrates the corresponding issues.

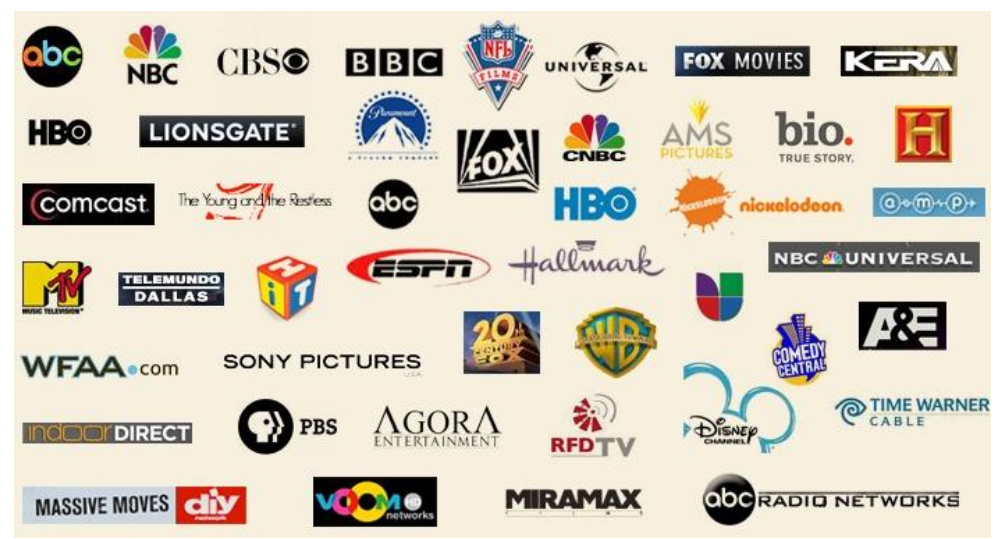

Figure 2. The Famous Brand and Companies of Hollywood 


\section{The Development of the CG Techniques.} CG belongs to the computer digital image technology, the technology and digital technology is very closely with the primary main features. CG technology application field of graphic design can significantly simplify working process, work efficiency raised, rich variety of visual art effect of works are shown. CG technology combined with other computer technology development, derived virtual reality, a lot of visual art before the expansion.

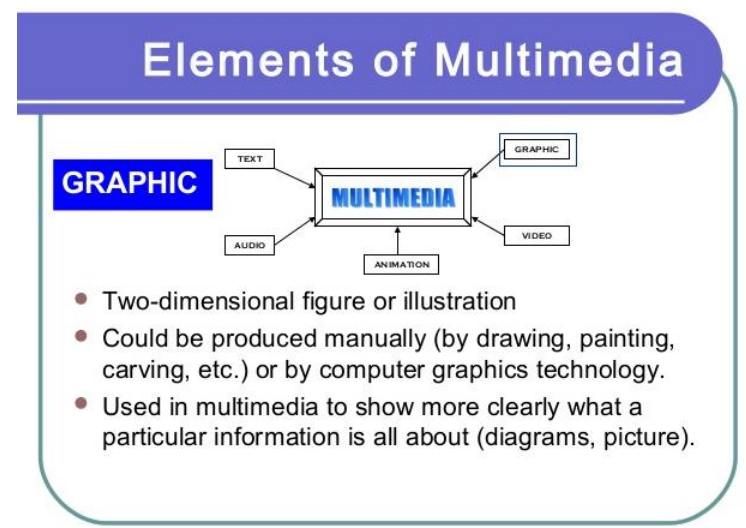

Figure 3. The CG and Multimeadia Technique Development

CG technology if free from the artistic expressive force, its life is short. CG is supposed to be the perfect combination of art and technology, the correct view of the technical of the CG animation and artistic quality. CG is not crucial for the development of the industry how high is the application technology of science and technology content, the quantity is not more show the huge investment. CG work artistic expression and the power, and improve the CG industry overall technical level and the aesthetic accomplishment, effectively improve the level of writing and producing, is we should strive to direction and pursuit. The eyes of the audience is more and more picky, domestic CG can reach the international level, can let the audience to trust our technical ability and the artistic expression is we must face the challenge. Content production, broadcast, TV receiving system under the condition of the old and new coexist, analog and digital technology in the production stage, the television program manufacture personnel that making CG images using the computer technology in viewing phase, the mainstream of the end user through the television receiver video analog television reception. In terms of moving the images show, TV receiver and the computer screen display screen has many technical differences, such as rendering of clarity, scanning frequency, color space, display area and the pixel width to height ratio and so on, of the differences between the two caused by a variety of the different image rendering. Considering final viewing users viewing quality, television program manufacture personnel in writing for television back CG images, should give full consideration to the differences between the two together with the general optimization of CG images with specific processing.

The Film and Television Production. The film and television culture is a kind of the sound by drawing on the screen image of cultural forms of activities that is both science and art attribute of the aesthetic culture. It is both a category, multi-level and the most modern form, human culture is a kind of based on audio-visual technology of the development of mass culture. It is the embodiment of the culture of society as a whole as has a national and regional psychological structure, aesthetic interest, spirit, consciousness and so on traditional steady structure and full of youthful spirit of the show the diachronic characteristics of the spirit of the times of the change at the same time, it also has the specialized cultural identity that have a distinctive personality and its own laws [8].

With the development of the film art, film and television model is increasingly showing its unique charm and immeasurable prospects, and film and television is also with new ideas and primary new technology new ceaselessly, attaches the great importance to the high and new technology the perfect combination of art and increasingly, that shaking up the people of the audio-visual. This wind, the mightiest of making film workers should have to think about the film 
and television post-production how out of a road, how to fast economic and efficient it becomes widespread, how to use, then make post-production and shooting skills, and basic industry become a hot topic, film and television of the high-tech use also makes the study of film and television production staff have to deep.

The film and television post-production brought very strong shock effect for film and television works, and in the work of these effects is past impossible anyway. The development of the computer for the development of film and television post-production, bring infinite development as can say is optimistic outlook. More and more of the directors and the producers have noticed in the film and television post-production has an important position that cannot be ignored. With the improvement of people appreciate level will be more and more demand for film and television works, to fully realize the audience's imagination and demand in the heart, only with the traditional ordinary film technology has been unable to meet. These should be done by the film and television post-production, with the improvement of modern computer technology, the level of film and television post-production also will be more and more high and this is the market demand development of film and television work.

The Future of Chinese Film. Film songs as an important part in the film and television works is the soul of the film and television play, sometimes songs to the impression of is more than the content itself. This not only because film songs from beginning to end in the film and television works, it and pictures together to the audience the visual and auditory sensory effects, the development of the plot and climax to sublimate in the music, the audience's emotions to muster in music, so as to achieve the aim of infected with the audience. It is hard to imagine a film and television works from beginning to end all have no what score will be effect, more wonderful plot may also appear dim because of this, and excellent music works is the nods eyeball pen of film and television drama.

Brand is the important condition and driving force of the development of the cultural industry, only a brand, film and television industry chain of low-end base can truly walk was born. Trends, from the competition in today's market competition between basic film and television base, have crossed the competitive products and service stage, entered the era of brand competition. Film and television base to win the market, it must go the way of the brand construction and we must build strong competitive brand. Film and television works of art to drive and promote the consumption of literature, literary consumption also laid a solid foundation for the film and television art. The two complement each other that be short of one cannot. They not only satisfy the people's growing cultural consumption demand, but also to strengthen the development of socialist spiritual civilization construction to promote social harmony. The transformation of Chinese society system, the emergence of the mass culture and popular culture consumption market, brought profound changes to the modern culture and literature with the situation of the multicultural coexistence. Popular and the elegant art has its own development space, the two parallel. The production of literature and art under the condition of the socialist market economy should not only attach importance to economic benefit, need more attention to social benefits, as social production activities of spiritual culture.

\section{Conclusion}

In this paper, we conduct research on the developmental trend of CG technology in Hollywood and the influence on Chinese film and the television production. $\mathrm{CG}$ animation in the decades of the rapid development in the stark image visual features, the new calculation of production technology and application, constantly inspire $\mathrm{CG}$ animation creator 
innovative visual representation to create means to update the change and the visual consciousness, make CG animation image visual representation is under a certain characteristics of constant development, constantly forming new features. No matter how to change, in the form of the expression and visual sense and innovation is the largest source of animation art charm, and the pursuit of basic visual psychological feeling strong, vivid and lifelike animation is always the target of the creator. Our future research will be focused on the corresponding advancement of CG technique to form the better suggestion for industry development.

\section{References}

[1] Foster, Pacey, Stephan Manning, and David Terkla. "The rise of Hollywood East: regional film offices as intermediaries in film and television production clusters." Regional Studies 49.3 (2015): 433-450.

[2] Stewart, Michael. "Introduction: Film and TV Melodrama: An Overview." Melodrama in Contemporary Film and Television. Palgrave Macmillan UK, 2014. 1-21.

[3] Medjesky, Christopher. "Transmedia Television: New Trends in Network Serial
Production." Journalism and Mass Communication Quarterly 91.1 (2014): 197.

[4] Kapell, Matthew Wilhelm. "Screens of Blood: A Critical Approach to Film and Television Violence Gregory Desilet. Jefferson, NC: McFarland, 2014." (2015): 309-310.

[5] Chow-White, Peter A., Danielle Deveau, and Philippa Adams. "Media encoding in science fiction television: Battlestar Galactica as a site of critical cultural production." Media, Culture \& Society 37.8 (2015): 1210-1225.

[6] Kelly, Rachael. "Europa Report by Sebastián Cordero (review)." Science Fiction Film and Television 7.3 (2014): 437-441.

[7] Tovey, Derek. "The collar: Reading Christian ministry in fiction, television, and film [Book Review]." Stimulus: The New Zealand Journal of Christian Thought and Practice 22.2 (2015): 57.

[8] McNaughton, Douglas. "Video Film Recording: A New Production Paradigm For 1960s BBC Drama." Historical Journal of Film, Radio and Television 34.3 (2014): 390-404. 